\title{
Correspondence
}

Journal of Medical Genetics 1989, 26, 346-349

\section{Short rib syndrome without polydactyly}

SIR,

Dr Winter has recently reported a third case of a lethal short rib syndrome without polydactyly, ${ }^{1}$ first reported by Beemer $e t a l^{2}$ in two unrelated infants, one of whom subsequently had an affected sib. Not only does this entity differ from the short ribpolydactyly syndromes by virtue of the absence of polydactyly, but also because of its distinct clinical and radiological features. Histological findings were not recorded in any of these three infants.

We have recently observed a similarly affected female infant, who was the second child born to a 27 year old mother and her unrelated 19 year old husband. Their first child was healthy. Intrauterine ascites was noted ultrasonographically at 34 weeks. Labour was induced at term. At birth the baby weighed $3000 \mathrm{~g}$ (10th centile), was $42 \mathrm{~cm}$ long $(<<3$ rd centile), and had a head circumference of
$37.5 \mathrm{~cm}$ (97th centile). The baby was noted to have $\cong$ gross limb shortening and lived only three hours. \& Additional external abnormalities (fig 1) included a $\vec{\circ}$ very large anterior fontanelle, flat nasal bridge with anteverted nares, narrow philtrum, high arched $\vec{\omega}$ palate with prominent midline groove, narrow chest, and distended abdomen. There was no polydactyly and no internal anomalies were noted at i necropsy other than moderate ascites. The umbilical of cord showed three vessels and oedema at its point of $\omega$ attachment to the umbilicus (fig 1). Chromosome of studies showed a normal female karyotype.

Radiography (fig 2) showed strikingly short hori- zontal ribs with widening anteriorly, high clavicles, $\bar{z}$ small scapulae, short tubular bones with smooth, rounded metaphyses, mild bowing of the humeri $\vec{\varphi}$ and tibiae which were longer than the fibulae, and ${ }_{0}^{\circ}$ marked bowing of the radii and ulnae.

Histological examination showed large vascular channels surrounded by sleeves of loose connective

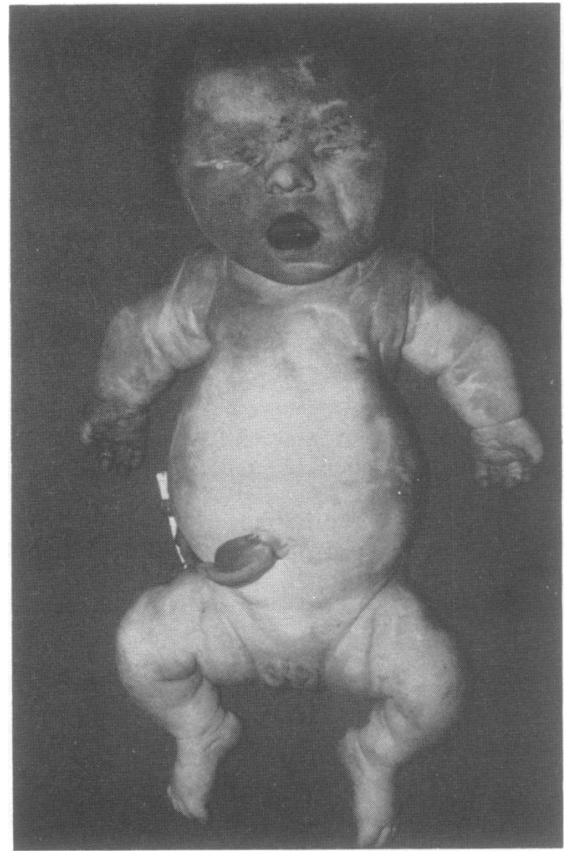

FIG 1 Post mortem view of the baby.

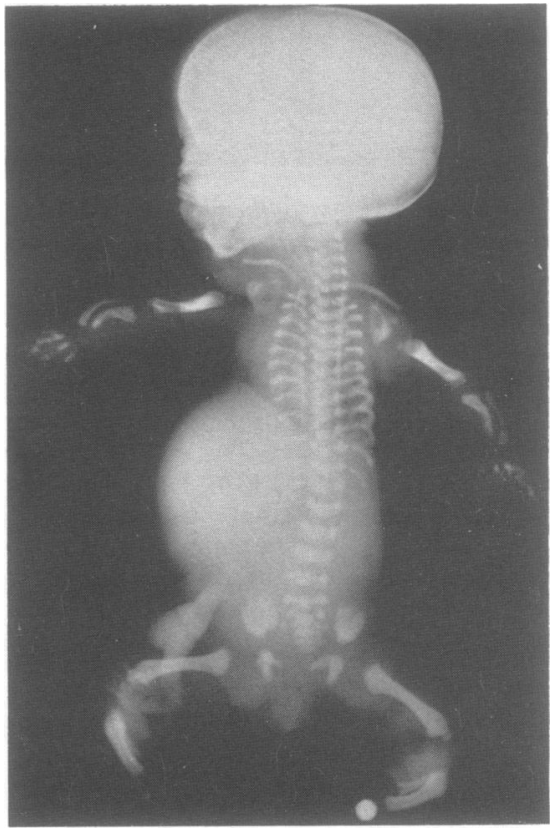

FIG 2 Whole body radiograph of the baby. 


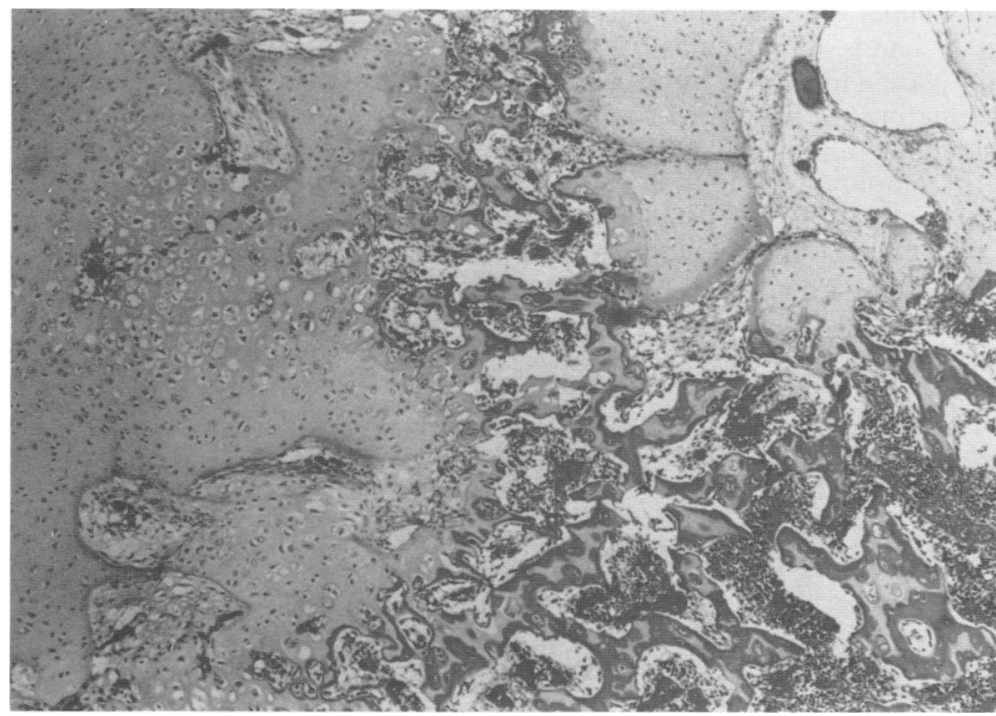

FIG 3 Photomicrograph of growth plate from head of femur.

tissue in the femoral epiphysis (fig 3). The growth plate showed focal chondrocyte proliferation overlying irregular zones of chondrocyte hypertrophy with poor column formation. Ossification was irregular and trabeculae coarse. Large islands of residual cartilage were present in the metaphysis.

The findings in this baby correspond closely to those in the infants described by Winter ${ }^{1}$ and by Beemer $e t a l,{ }^{2}$ and support their contention that this constitutes a separate short rib syndrome. In particular, the radiological changes are not typical of any of the well recognised short rib-polydactyly syndromes, in which there may occasionally be absence of polydactyly. ${ }^{3}$ However, our observations of an irregular growth plate and large vascular channels in epiphyseal and metaphyseal cartilage are in keeping with other histology reports in babies with lethal short rib-polydactyly syndromes and do not appear to be specific for this particular condition.

\section{K Chen*, P A McKeever*, AND I D Young $\dagger$ Departments of Pathology* and Child Healtht, Leicester Royal Infirmary, Leicester LE2 $7 L X$.}

\section{References}

1 Winter RM. A lethal short rib syndrome without polydactyly. J Med Genet 1988;25:349-50.

2 Beemer FA, Langer LO, Klep-de Pater JM, et al. A new short rib syndrome: report of two cases. Am J Med Genet 1983;14: 115-23.

${ }^{3}$ Sillence DO. Non-Majewski short rib-polydactyly syndrome. Am J Med Genet 1980;7:223-9.
Van der Woude syndrome and limb defects: the chance of recurrence

SIR,

Küster and Lambrecht (J Med Genet 1988;25:565-7) reported the association of cleft lip and palate, lower lip pits, transverse deficiency of the hands and feet, syndactyly of the fingers, and club foot. It was speculated that the hand and limb defects could represent previously unrecorded effects of the Van der Woude syndrome. The pregnancy was significant in that there was premature rupture of the membranes from 31 to 35 weeks, when the patient was born. Amnion rupture has a well recognised association with limb deficiency, syndactyly, and club foot. ${ }^{1-4}$ There have been an extensive number of experimental studies looking at the association of amniotic sac rupture and limb deficiency and Kennedy and Persaud ${ }^{5}$ proposed a hypothesis based on the experimental work which indicated that the initial lesion from amniotic sac rupture is a vascular one produced by uteroplacental insufficiency either by compression of the umbilical cord or by compression of the placenta itself. Houben ${ }^{6}$ analysed by histological study the limb haemorrhage produced by amniocentesis in the rat and showed that the endothelial rupture of the marginal vein was the initial event, followed by blebs, perivascular oedema, and vascular congestion.

Torpin ${ }^{1}$ felt that the limb deficiency was the result of mesodermic fibrous strings, produced after amnion rupture, wrapping around the limbs. This 